\title{
Reliability study for rib index
}

\author{
Konstantinos C Soultanis ${ }^{1 *}$, Konstantinos Tsiavos ${ }^{1}$, Theodoros B Grivas ${ }^{2}$, Nikolaos A Stavropoulos ${ }^{1}$, \\ Vasileios I Sakallariou', Andreas F Mavrogenis ${ }^{1}$, Panayiotis J Papagelopoulos ${ }^{1}$ \\ From The 10th Meeting of the International Research Society of Spinal Deformities (IRSSD 2014 Sapporo) \\ Sapporo, Japan. 29 June - 2 July 2014
}

\section{Objectives}

The Rib Index, (RI), extracted from the double rib couture sign (DRCS) on lateral spinal radiographs to evaluate rib hump deformity in IS patients has been earlier introduced (Grivas at al 2000). Although various papers using the RI have been published, no study of its reproducibility was reported. To estimate the variations of the RI in a number of a pair set of lateral chest radiographs of healthy volunteers. The hypothesis was that the RI should have minimal variability for each patient having successive lateral radiographs.

\section{Methods}

70 randomized patients were initially included in the study. Each of these patients has two consequent chest lateral radiographs (LRs) at the radiological department of our hospital, by the same technician, during the course of treatment, (named A and B group of LRs). The radiation source - patient distance was constant. All LRs obtained in an incorrect position of the patient and LRs of those who underwent a thoracic intervention were excluded. In 49 patients A and B LRs were found to be suitable for assessment. The RI was calculated in both LRs of each patient. The statistical analysis included the paired t-test in the set of LRs, its correlation coefficient (R2), the intra- and inter-observer error using the formula (SD/V2)/2, where SD is this of the differences of the two sets of measurement (As-Bs). The SPSS v16 statistical package was used.

\section{Results}

In the 49 pairs of LRs there was no statistical difference of the RI, (paired t-test $\mathrm{p}<0.314$ ). The RI in the A and B group of LRs was perfectly correlated (correlation coefficient $R=0,924, p<0.0001$ ). The intra-observer error was 0.0080 while the inter-observer error was 0.0213 .

${ }^{1}$ 1st Orthopaedic Department, Athens University, Medical school, Greece Full list of author information is available at the end of the article

\section{Conclusion}

The RI proves to be a reliable method to evaluate the thoracic deformity or the effect of surgical or conservative treatment on the IS rib-cage deformity (hump). IR is a simple method, a safe reproducible way to assess the rib hump deformity based on lateral radiographs, without the need for any other special radiographs and exposure to additional radiation.

\section{Authors' details \\ ${ }^{1} 1$ st Orthopaedic Department, Athens University, Medical school, Greece. ${ }^{2}$ Department of Orthopaedics and Traumatology, TZANEIO General Hospital of Piraeus, Piraeus, Greece.}

Published: 19 January 2015

doi:10.1186/1748-7161-10-S1-047

Cite this article as: Soultanis et al:: Reliability study for rib index. Scoliosis 2015 10(Suppl 1):047.
Submit your next manuscript to BioMed Central and take full advantage of:

- Convenient online submission

- Thorough peer review

- No space constraints or color figure charges

- Immediate publication on acceptance

- Inclusion in PubMed, CAS, Scopus and Google Scholar

- Research which is freely available for redistribution
() Biomed Central
C Biomed Central

(c) 2015 Soultanis et al; licensee BioMed Central Ltd. This is an Open Access article distributed under the terms of the Creative Commons Attribution License (http://creativecommons.org/licenses/by/4.0), which permits unrestricted use, distribution, and reproduction in any medium, provided the original work is properly cited. The Creative Commons Public Domain Dedication waiver (http://creativecommons.org/publicdomain/zero/1.0/) applies to the data made available in this article, unless otherwise stated. 